\title{
1874 Ankara kuraklığına bir manzume: Kasîde-i Kahtyyye
}

\begin{abstract}
APA: Yörür, A. (2019). 1874 Ankara kuraklı̆̆ına bir manzume: Kasîde-i Kahtıyye. RumeliDE Dil ve Edebiyat Araştırmaları Dergisi, (14), 289-297. DOI: 10.2900o/rumelide.541021

\section{$\ddot{O} \mathbf{z}$}

Kuraklık, yağışların normal seviyelerinin önemli ölçüde altına düşmesiyle ortaya çıkan ve herhangi bir zamanda, herhangi bir yerde meydana gelebilecek olan doğal bir iklim olayıdır. Kuraklık, dünyanın birçok yerinde farklı dönemlerde görülmüş ve kuraklığın sonucu olan kıtlık olayları yaşanmıştır. Avrupa'da 18. Yüzyılın ilk yarısında yaşanan doğal afetler ciddi kıtlıklara yol açmıştır. Benzer olaylar yine farklı zaman dilimlerinde Osmanlı devletinde de görülmüştür. Doğal afetlerden biri olan kuraklık sonucu Ankara'da oluşan zahire sıkıntısı, hububat eksikliği nedeniyle halkın yeterince beslenememesinden kaynaklanan ölümler artmış ve halk yakın yerlere göç etmiştir. Kuraklıktan dolayı kuruyan su kaynakları nedeniyle merkezdeki su sıkıntısı artmış, bölge halkının sağlığa uygunluk koşullarını sağlayamamasından dolayı hastalıklar ortaya çıkmıştır. Bu makalede 19. yüzyılda Ankara'da yaşanan kuraklık ve kıtlık hakkında bilgi verilmiş, Çerkeşîzade Mehmed Tevfîk Efendi’nin hayatı ve eserleri üzerinde kısaca durulmuştur. Şairin, 1874 yılında Ankara'da yaşanan kuraklık üzerine yazdığg Kasîde-i Kahtıyye'nin transkripsiyonlu metni, günümüz Türkçesine çevirisi verilmiş ve incelemesi yapılmıştır.
\end{abstract}

Ali YÖRÜ'R

Anahtar kelimeler: Kaside, Kahtıyye, Çerkeşîzâde Mehmed Tevfîk Efendi, kuraklık.

\section{A poem for the Ankara drought of 1874: Kasida-i Kahtiyya}

\begin{abstract}
Drought is a natural climate event that can occur anywhere and at any time as a result of belowaverage precipitation. Drought has been observed throughout many parts of the world at different periods and has lead to famine events. The natural disasters that took place during the first half of the $18^{\text {th }}$ Century in Europe resulted in serious famine events. Similar events had been observed throughout the Ottoman Empire at different time slices as well. Taking place in Ankara, drought, being of natural disasters, resulted in a severe shortage of grain, death caused by malnutrition of people because ofcereals, migration of people to nearby regions, children being left orphaned, the drying of water resources due todrought thus leading to extreme water shortages in the centre of the province, as well as the emergence of diseases due to inadequate health conditions of the people. This paper both provides information about the drought and famine experienced in Ankara in the $19^{\text {th }}$ century, as well as briefly mentionsabout the life and works of Çerkeşizade Mehmed Tevfik Efendi. A transcribed version of his Kasîde-iKahtıyye about the drought in 1874 in Ankara, has been translated into Modern Turkish and examined.
\end{abstract}

Key words: Kasida, Kahtiyya, Çerkeşîzâde Mehmed Tevfîk Efendi, drought.

1 Dr. Öğrencisi, Trakya Üniversitesi, Sosyal Bilimler Enstitüsü, Türk Dili ve Edebiyatı ABD, (Edirne, Türkiye), ali.yorur@hotmail.com, ORCID ID: oooo-00o3-1434-2995 [Makale kaylt tarihi: 09.02.2019-kabul tarihi: 14.03.2019; DOI: $10.29000 /$ rumelide. 541021] 


\section{Giriş}

Kuraklık, dünyanın birçok bölgesinde aynı veya farklı zaman diliminde görülen bir olaydır. Kuraklığın doğal sonucu olan kıtlık, bölge halkı için en tehlikeli doğal afet olarak kabul edilir. Çünkü kuraklıkla beraber bölgede suların azalması bitkilerin yok olmasına, halkın zamanla zahiresiz kalmasına, hayvanların telef olmasına neden olmaktadır. Ekonomileri daha çok tarıma dayanan devletlerde, kuraklığın uzun veya kısa sürmesi ve arka arkaya tekrarlaması beraberinde yıkıcı olabilecek sonuçların yaşanmasına neden olmuştur (Tümertekin 1955: 127). Osmanlı Devleti’nde halkın büyük bir bölümü çiftçilikle geçimini sağlamaktaydı. Yağışın az olduğu dönemlerde tarımla uğraşan kesim hasatta büyük kayıplara uğramaktaydı (Akkemik; Köse 2005: 129). Kuraklığın yaşandığı bölgelerde halk, kuraklıktan etkilenmeyen veya daha az etkisinin görüldüğü bölgelere taşınmıştır. Göç hadisesi nedeniyle bölge halkının arazisi boş kalmakta ve tarımsal üretim azalmaktaydı. Bu da tarımsal ürünlerden alınan verginin düşmesine neden olmaktaydı (Karaboğa 2012: 327).

\section{Ankara'da kuraklık ve kıtlık}

Osmanlı Devleti 1845 ve 1874 yıllarında iki büyük kuraklık ve sonucunda da kıtlık yaşamıştır. Yaşanan kuraklıklar Osmanlı Devleti’nin birçok yerinde olduğu gibi Anadolu'da da Ankara, Konya ve Bursa'da etkisini göstermiştir. Kuraklığa bağlı olarak ortaya çıkan kıtlık bölgenin tarımsal faaliyetlerinin büyük ölçüde düşmesine ve dolayısıyla tahıl ürünlerinde pahalılık yaşanmasına, hayat şartlarının zorlaşmasına neden olmuştur. Anadolu coğrafyasında kuraklık, 1839 senesinde ilk belirtilerini göstermiştir. Bu durum karşısında Ankara yerel idaresi tarafından hükümet depolarında bulunan hububat halka dağıtılmıştır. Yerel idare böylelikle hububattaki fiyat artışını durdurmak istemiştir. 1845 senesindeki kuraklık ve kıtlık Ankara suyunun çekilmesine neden olmuştur. Bunun üzerine halkın istekleri doğrultusunda Ankara suyu üzerine bir bent inşa edilmiştir. Bir önceki sene yağışın az olmasından kaynaklanan üretimin azlığı ve 1845 yaz mevsiminin oldukça sıcak geçmesinden ötürü bölge halkının önceki senenin mahsullerini bitirmiş olmaları kitlı̆̆ın yaşanmasına neden olmuştur. Yaşanan kitlık neticesinde Ankara ve yakın çevresi yardım talebinde bulunmuştur. Yöre halkının ihtiyaçlarının giderilmesi konusunda hükümetten de yardım talebinde bulunulmuştu. Ankara'da yaşanan kuraklık ve neticesinde kıtlık karşısında hükümet Ankara'nın yanı sıra Bursa ve Bolu'ya da yardım edilmesi için çalışmalara başlamıştır. Diğer bölge halklarının ve hükümetin kıtlığın olumsuzluklarını giderme çalışmaları yeterli olmamış, açlık nedeni ile Ankara ve çevresinde hem insan hem de hayvan ölümleri yaşanmıştır. Zorlaşan yaşam şartları nedeniyle Ankara'nın kuraklıktan etkilenen sancak ve kazalarından vilayet merkezine göç hareketi yaşanmıştır (Altındaş 2018: 4).

Osmanlı Devleti'nde etkisini gösteren bir diğer kuraklık ise 19. yüzyılın son çeyreğinde yaşanmıştır. 1869-1870 yılları arasında havaların oldukça sıcak geçmesi nedeniyle çiftçi ürün alamaz duruma gelmiştir. Ankara vilayetinde 1873-1874 senelerinde kış aylarının çok sert geçmesi ve kuraklığın etkisinin devam etmesi yöre halkını tohumluk buğday stoklarını tüketmek zorunda bırakmıştır ( Altındaş 2018: 5). Osmanlı Devleti'nin birçok bölgesinde kuraklık yaşanmasına rağmen ortaya çıkan kıtllktan en çok etkilenen yer Ankara ve Konya olmuştur (Erler 2012: 151). Oldukça zor şartlar altında geçen kış mevsiminden sonra yaşanan kuraklık neticesinde Ankara vilayeti genelinde elde edilen ürün önceki yılların onda biri kadardı. Hükümet bölge halkının ihtiyacını karşılamak için çalışmalara başlamasına rağmen nakliyatta karşılaşılan zorluklar nedeniyle zahire zamanında getirilememiştir. Hükümet Ankara'nın et ihtiyacının karşlanabilmesi için öncelikle yakın olan yerlerden küçükbaş hayvan nakledilmesini istemiştir. Fakat hükümetin bu isteği Kastamonu başta olmak üzere diğer yerlerde de hoşnutsuzluğa neden olmuştur. Kıtlık nedeniyle halkın yetersiz beslenmesinden dolayı 
bünyeler zayıf düşmüş ve beraberinde de salgın hastalıklar gelmiştir. Kıtlık yaklaşı 18.000 insanın ölümüne neden olmuştur (Altındaş 2018: 5). Anne ve babaları kıtlıktan dolayı vefat eden çocuklar, askeri kışlada ihtiyaçlarının giderilebilmesi için toplanmıştır. Ama çocuklara kışlada sağlıklı bir ortam sağlanamaması üzerine bir ıslahhanenin kurulması için çalışmalara başlanılmıştır (Koç 2007: 127). Daha sonra Ankara'da aileleri vefat eden 100 kadar çocuk Ankara Valisi tarafından bakılmaları için yerli ailelere verilmiş ve ihtiyaçları hükümet tarafından karşılanmıştır (Erler 2012: 156).

1874 kıtllğıyla beraber Ankara kaza ve sancaklarından Ankara merkezine doğru bir göç hareketi yaşanmıştır. Ankara merkezine yaklaşık olarak 4.000 kişi göç etmiştir (Erler 2012: 157). Ama Ankara'nın yakın çevresinden yapılan göçler sonucunda umduğunu bulamayan halk yeniden göçe hazırlanmış ve yaklaşık olarak 30.000 kişi Adana, Bursa, Kastamonu, Sivas, Gümüşhane, Samsun, Tokat, Erzurum, Düzce, Bergama, Adapazarı, İzmit, İstanbul ve Halep’e gitmiştir (Erler 2012: 181).

1874 yılındaki kıtlık sonucu yaşanan açlık Ankara ve yakın çevresinde salgın hastalıkların (tifüs, sıtma, humma) ortaya çıkmasına da neden olmuştur. Bu hastalıkların tedavi edilmesi için İstanbul'dan Ankara'ya doktor, eczacı ve tıbbi malzeme gönderilmişse de yapılan yardımlar yetersiz kalmıştır. Hastaların düzenli bir şekilde tedavi edilebilmesi için uygun hastanenin olmayışı nedeniyle süvari ve piyade kışlaları kullanılmıştır (Erler 2012: 168).

Ankara'da kuraklığın etkisiyle su sıkıntısı ortaya çıkmış dolayısıyla değirmenler çalıştırılamamıştır. Bu durum da un ve ekmek fiyatlarının yükselmesine neden olmuştur. Mağdurlar için Ankara’ya gönderilen hububatın işlenememesinden dolayı halk ekmek yapamamıştır. Kıtlığın bir sonucu olarak yardımların zamanında yapılabilmesi için şose yolların önemi artmış ve bu konuda çalışmalara başlanılmıştır. Nakliye işlemlerinin deve, katır gibi yük hayvanlarıyla yapılması oldukça masraflı olmaktaydı. Dolayısıyla bu durum da yardım yapan yerel idare bütçelerinin zayıflamasına sebep olmuştur. Bu nedenle hükümet yardım için yapılan nakliye masraflarını mevcut gelir kaynaklarından karşılamak zorunda kalmıştır( Erler 2012: 300).

\section{Çerkeşîzâde Mehmed Tevfîk Efendi}

Çerkeşizâde Mehmed Tevfîk Efendi, Osmanlı âlimlerinden Osman Vehbi Efendi'nin oğludur. Dedesi Halvetiyye-Şabâniyye tarîkatı şeyhlerinden Mustafa Efendi'dir. 1242/1826 yılında Ankara'da doğmuştur. İlk tahsilini babasından almıştır. 1262/1846 yılında yükseköğrenimini tamamlamak için İstanbul'a giderek Vidinli Mustafa ve Hafız Seyyid Efendilerden ders almış ve icazet almaya hak kazanmıştır. Beşiktaş, Halep, Çankırı, Bursa, Balıkesir ve Mısır'da mevleviyet görevlerinde bulunduktan sonra Medine kadısı olmuş, daha sonra Ankara'ya dönerek on iki yıl müderrislik yapmıştır. Üç yıl İstanbul kadılığı yaptıktan sonra Rumeli kazaskerliği muavinliğine tayin edilmiş, aynı yıl Meclis-i Meşayih Nezareti reisi olmuş, 1889'da Anadolu, ertesi yl Rumeli kazaskeri payelerini almış ve şeyhülislamlığın Meclis-i Müellefat Encümeni başkanlığına tayin edilmiştir. Dedesi Çerkeşi Mustafa Efendi'nin tarikatına mensup olan Mehmed Tevfîk, şeyhülislam olmasına az kalmışken 1893 yılında vefat etmiş ve Aksaray Sofular'daki Ekmel Dergâhı'na defnedilmiştir (Kasâ’id-i Tevfîk 1304: 47; DİA 1993: 273).

Çerkeşîâade Mehmed Tevfikk Efendi, çoğu Arapça ve dinî konulu olan şu eserleri yazmıştır: Meziyyet-i İslâmiyye (İstanbul 1306), Gâyetü 'l-beyân fi-ilmi'l-mîzân (İstanbul 1306), Behcetü't-tarffi-ilmi's-sarf (İstanbul 1308), İcmâl-i Nahv-i Arabî, Hediyyetü's-sıbyân (İstanbul 1308), Miftâhü'l-akâid (İstanbul 1301), Levâyihü'l-kudsiyye fi-fezâili Şeyhü Ekber (İstanbul 1303), Mecmûa-i Fezâil, el-İtkân fi-tahkîki'l- 
îmân, Tahkîk-i İdrâkât, Risâlefi-kabûli'ttevbe. Şerh-i Akâid-i Nesefi Tercümesindeki Halâlara Dâir Risâle. Kasaid-i Tevfîk² (1286 Şam, 1304 İstanbul) (Eliaçık 2011: 60).

Miraciye'nin içinde bulunduğu Kasâid-i Tevfik'te yer alan konu başlıkları, beyit sayıları ve içerikleri şu şekildedir:

1. Tevhîd-i Bârî: 108 beyitlik bir kaside olup mefâilün mefâilün mefâilün mefâ̂llün kalıbıyla yazılmıştır.

2. Nazîre-i Nefî: Nefi'nin sözüm redifli kasidesine nazire olarak 109 beyitlik bir na't olup fâilâtün fâilâtün fâilâtün fâilün aruz kalıbıyla yazılmıştır.

3. Kasîde-i Vücûd Der-Medh-i Rasûl: 61 beyitlik bir na't olup feilâtün feilâtün feilâtün feilün aruz kalıbıyla yazılmıştır.

4. Kasîde-i İmkâniye Der-Hakk-ı Seyyidü'l-Kevneyn ve Rasûlü's-Sekaleyn Sallallâhü Aleyhi Ve Sellem: 39 beyitlik bir na't olup feilâtün feilâtün feilâtün feilün aruz kalıbıyla yazılmıştır.

5. Kasîde-i Miraciye: 47 beyitlik bir na't olup feilâtün feilâtün feilâtün feilün aruz kalıbıyla yazılmıştır.

6. Sahbâ-nâme-i Hakikat: 63 beyitlik bir na't olup feilâtün feilâtün feilâtün feilün aruz kalıbıyla yazılmıştır

7. Na't-ı Şerîf: 38 beyitlik bir na't olup feilâtün feilâtün feilâtün feilün aruz kalıbıyla yazılmıştır.

8. Mersiye Der-hakk-1 Hazret-i İmam Hüseyn: Her biri on beyitten oluşan yedi bentlik terkib-i bend şeklinde bir mersiye olup fâilâtün fâilâtün fâilâtün fâilün aruz kalıbıyla yazılmıştır.

9. Kasîde-i Rahşiye Der-Medh-i Sultân 'Abdü'l-Azîz Hân: 69 beyitlik bir kaside olup feilâtün feilâtün feilâtün feilün aruz kalıbıyla yazılmıştır.

10. Kasîde-i Kahtiye: 36 beyitlik bir kaside olup Ankara'nın kıtlı̆̆ı için feilâtün feilâtün feilâtün feilün aruz kalıbıyla yazılmıştır.

11. Der-Medh-i Sultân-ı Zamân Abdü'l-Hamîd Hân Dâme Mülkuhû: 39 beyitlik bir kaside olup feilâtün feilâtün feilâtün feilün aruz kahıbıyla yazılmıştır.

12. Der-Medh-i Sultân-ı Abdü'l-Hamîd Hân Dâme Mülkuhû: 49 beyitlik bir kaside olup mefâ̂lün mefâ̂lü̈n mefâillün mefâillün aruz kalıbıyla yazılmıştır.

13. Şeyhü'-İslam Muhammed Sa'de'd-dîn Efendi Hakkında Söylenmiştir: 48 beyitlik bir kaside olup feilâtün feilâtün feilâtün feilün aruz kalıbıyla yazılmıştır.

14. Hâlâ Mesned-Nişîn-i Makâm-ı Meşîhat-i Ulyâ ve Semâhatlü Ahmed Es'ad Efendi Hazretleri Hakkında Söylenmiştir: 41 beyitlik bir kaside olup mefâ̂lün mefâ̂llün mefâ̂lün mefầlün aruz kalıbıyla yazılmıştır.

15. Kasîde-i Bahâriye Der-Hakk-ı Mûsâ Safvetî Paşa: 44 beyitlik bir kaside olup feilâtün felâtün feilâtün feilün aruz kalıbıyla yazılmıştır.

16. Nasîhatü'l-i̇hvân: 69 beyitlik bir mesnevi olup feilâtün feilâtün feilâtün feilün aruz kalıbıyla yazılmıştır.

Kasâid-i Tevfîk üzerine bir yüksek lisans tezi hazırlanmıştır. Şeyma Yaşil, "Çerkeşîââe Mehmet Tevfîk Efendi ve Kasâidi Tevfîk’’”. Ankara Üniversitesi Sosyal Bilimler Enstitüsü İ̀slam Tarihi ve Sanatları Anabilim Dalı, Ankara 2013. 
17. Şiire Nev-Heves İken Müşârün İleyh Safvetî Paşa Hakkında Söylenen İbtidâî Kasîdedir: 32 beyitlik bir kaside olup şairin şiire yeni başladığı sıralarda Musa Saffeti Paşa için fâilâtün fâilâtün fâilâtün fâilün aruz kalıbıyla yazılmıştır.

\section{Çerkeşîzâde Mehmed Tevfîk Efendi’nin Kasîde-i Kahtıyyesi}

Çalışmamıza konu olan Kasîde-i Kahtıyye, 1304/1887 yılında İstanbul'da Mihran Matbaası'nda basılmış olan Kasẩid-i Tevfik isimli eserinin içinde yer almaktadır.

Çerkeşîzâde Mehmed Tevfîk Efendi’nin manzumesi, 37 beyitten oluşmaktadır. Eser, kaside nazım şekliyle ve aruzun fe'ilâtün fe'ilâtün fe'ilâtün fe'ilün kalıbıyla yazılmıştır.

Çerkeşîzâde Mehmed Tevfîk Efendi kasideye, Allah’ın kullarını terbiye etmek için Ankara’ya büyük bir kuraklık verdiğini söyleyerek başlamaktadır:

Terbiyet-bahş-ı ‘ibād olmaḳ içün Rabb-i ‘alīm

Anḳara şehrine virdi bu sene ḳaḥț-ı 'aẓīm

Kuraklık zamanında gökten yağmur yerine ateş yağmış, yeryüzü sıcaktan kavrulmuştur. Toprak sıcaktan çatlamış, hava cehennem gibi sıcak olmuştur:

Yere şebnem yerine yağdı hevādan āteş

Nāra garḳ oldı zemīn tā küre-i bād-ı nesīm

Çāk çāk oldı ḥarāretle zemīniñ bağrı

Tāb-nāk oldı hevānıñ yüzi mānend-i cahīm

Ankara'daki kuraklık Sultan Abdülaziz döneminde meydana gelmiş ve kaside ona yazılmıştır. Abdülaziz’in yardımıyla kıtlıktan eser kalmamıştır:

O şehinşāh-ı cihān 'Abdü'l-'azīz-i devrān

Rīze-hู`ār -ı kerem ü luṭi anıñ çerh̆-ı le’īm

Ḳalmadı hāl-i tezelzülden eserer ‘ālemde

İdeli ḳuvve-i ḳudsiyyesi mülki taḥkìm

Şair kasideyi, Sultan Abdülaziz'e sabah akşam dua ettiğini, Allah'ın sultanın kendisini ve evladını daima korumasını istemektedir:

İdelim şām u seḥer ḩayr dưā ey Tevfiḳ

Böyledir ‘ādet-i derīne-i her 'abd-i kadīm

Ḥıfẓ ide zāâtını evlādını Mevlā dā’im

Tā ki ma'mūr ola küngüre-i 'arşs-1 'aẓim

37 beyitlik Kasîde-i Kahtıyye'nin günümüz Türkçesiyle ifadesi şöyledir: 
Her şeyi bilen Allah, kulları terbiye etmek için bu sene Ankara şehrine büyük kuraklık verdi. Merhametsiz olan feleğin cismi kaza kılıcı ile ikiye ayrılarak eteği kanla dolsun. Nice yıllardır yağmur nimetini veriyordu. Eyvah ki bu yll susuzluk sebebiyle bağ ve bahçeler sararıp soldu. Hayli zamandan beri yağmur bulutları yok oldu. Acaba Kaf dağının arkasına mı çekildiler? Yere çiğ yerine havadan ateş yağdı. Yeryüzü ateşlere gark oldu. Toprak, sıcaktan yarıldı ve hava cehennem gibi sıcak oldu. Dağlar her yönden siyah matem elbisesine büründü, nehirler boş kaldı ve bahçelerde fidanlar kurudu. Menekşe başı eğik bir şekilde mahzun ve düşüncelidir. Lale acılarla yaralanmış, gonca çok sıkıntılı. Çadır çiçeği çadırında saklanarak dünya bahçesine yokluğun sırrını anlatıyor. Yaseminin boyu bükülüp teni harap oldu. Paramparça olmuş göğsü iyileşmez. Birçok zamandır açan çiçekler karardı ve kurudu. Bütün ağaçlar kurudu, yok oldu. Yalnız selvi ayakta kaldı. Güzel sesli bülbülün ağzı dili kurudu. Sadece suzinak makamını söylemektedir. Bütün Hüdhüd’ler susuz kaldı ve Seba'ya hicrete azmettiler. Dünyanın güneş ve ay gözü böyle gönül yakan bir vahim hal görmedi. Süt şeker birçok nimetler yok oldu. İnsanlar çöp ve süprüntüleri yiyerek çok sıkıntı çekti. O zaman Ankara'da can pazarı olmuştu. Herkes evladını yokluktan zehirlerdi. Sonra Allah'a şükürler olsun ki ferahlık geldi ve âlemi sevince boğdu. Yani kerem sahibi padişahın haberi olunca Ankara'yı ihsana boğdu. O öyle bir şahtır ki devleti ve tahtı üzere şaşa ve zenginlik bahşeder. Yine o öyle bir padişahtır ki onun eli cevher saçar. O su gibi çeşitli nimetler verip Ankara'yı gıpta edilecek yer haline getirdi. O dünyanın padişahı Abdülaziz Han'dır. Onun lütuf ve keremiyle alçak felek dökülüp kırılmıştır. Onun her yeri yapıp tahkim etmesiyle eski durumdan eser kalmadı. Ey cihanın hükümdarı! Senin lütuf ve keremin olmasaydı biz yok olup giderdik. Senin ihsanın bize hayat verdi. Senin bir nazarın isabet etse mermer döşemeleri iksir gibi altın ve gümüş eder. Eğer senin kokunu saba her yere dağıtsa cennet bekçileri keyif ile kendinden geçer. Sadece bize değil bütün dünyaya senin hükmün yayılmıştır. Hindistan, Sind Eyaleti, Yemen, Belh, Buhara, Afganistan sık sık senden yardım istemektedirler. Biz de teşekkür ifade etmek için bu kasideyi takdim eyledik. Ey Tevfik! Sabah akşam hayır dua edelim. Allah onu, evladını korusun.

\section{METIN}

\section{Kașīde-i Kahạtıyye}

Féilātün Fe'ilātün Fe'ilātün Fe'ilün

1. Terbiyet-bahş-ı 'ibād olmaḳ içün Rabb-i 'alīm

Anḳara şehrine virdi bu sene ḳahț-1 ‘azịm

2. Merhametsiz felegiñ dāmen[i] pür-hūun olsun

Kesilüp tìğ-i ḳażā ile ola cismi dū-nīm

3. $\quad$ Nice yllardır idüp ni'met-i bārānı dirìg

Șararup ṣoldı șusuzluk ile her bāg̀-ı naīm

4. Māverā-yı cebel-i Ḳāf'a mı çekdiler 'aceb

Haylī demden beridir ebr-i mațîr oldı 'adīm

5. Yere şebnem yerine yağdı hevādan āteş

Nāra garḳ oldı zemīn tā küre-i bād-ı nesīm 
6. Çāk çāk oldı harāretle zemīniñ bağrı

Tāb-nāk oldı hevānıñ yüzi mānend-i cahīm

7. Kūhler oldı siyeh-pūşī vü mātem-i her-sū

Cūylar ḳaldı tehī naḩl-i çemen-zār elīm

8. Ser-fürū bürde benefşe mütefekkir maḥzūn

Lāle pür-dāg̀-ı elem ġonce pür-endūh u sakīm

9. Oldı çadır çiçegi hayme-nişīn-i ihfāā

Gülşen-i dehre idüp sırr-ı fenā-yı tefhīm

10. Yāsemīniñ bükülüp ḳaddi harāb oldı teni

Eylemez sīne-i șad-çāki ḳabūl-i termīm

11. Haylī demdir ḳuşanup giydigi hep ezhārı̃

Kara ter-pūş u siyeh cāme siyeh ibrişīm

12. Oldı her dürlü şecer șaḥrā-yı 'adem

Yalıñız serv-i sehī pā-yı șbāt üzre muḳīm

13. Kuruyup ag̉zı dili bülbül-i hoş-elhānıñ

Sūzināk üzre ider şimdi hevā-yı taḳsīm

14. Teşne-leb ḳaldı bütün Hüdhüd-i zībende külāh

İtdiler tā be-Sebā-ı hicreti 'azm ü taṣmīm

15. Görmedi bāṣıra-i mihr ü mehi gerdūnuñ

Böyle bir hālet-i dil-sūz cihān emr-i vahīm

16. Oldı h ȟābīde-i mehd-i 'adem ü nā-būdı

Nice perverde-i şīr ü şeker ü nāz u na'īm

17. Haş u ḩāşāki tenāvül iderek nev'-i beşer

Oldı pür-derd ü elem ḳalmadı bir țab'-ı selīm

18. Ol vaḳt olmuş idi Anḳara cān bāzārı

Herkes evlādını yoḳluḳdan iderdi tesmīm 
19. Minnet Allāha ki geldi feraḥ u fevzī necāt ‘Ālemi eyledi garḳ-āb-ı sürūr u ten‘īm

20. Ya'nī ma'lūmı olunca şeh-i șāhịib-keremiñ Eyledi beldemizi maẓhar-ı ị̣sān-ı 'amīm

21. Ne şeh ol nūr-ı semāvāt ü zemīn-i devlet Ne şeh ol şa'şa'a bahşende-i taḥt u dīhīm

22. Ne şeh ol dest-i güher-pāşını eyler taḥsīn Menba'-ı nūr-ı tecellī yed-i beyżā-yı Kelīm

23. Eyleyüp șu gibi icrā ni'am-ı gūn-ā-gūn

Eyledi Anḳara’yı ġıțada bāğ-ı na‘īm

24. Dem-i luṭunda anıñ her ser-i engüşti olur Zümre-i ehl-i dile çeşme-i āb zer ü sìm

25. O şehinşāh-ı cihān 'Abdü'l-‘azīz-i devrān Rīze-hูª̄r -ı kerem ü luṭ̂ anıñ çerh-ı le’ìm

26. Kalmadı hāl-i tezelzülden eserer 'ālemde İdeli kuvve-i kudsiyyesi mülki tahkīm

27. Ey cihān-dār-ı mukaddes 'ilm-efrāz-ı vakāa Ve'y hudāvend-i kerīm ibn-i kerīm ibn-i kerīm

28. Olmasaydı kerem-i luṭ̂-ı cezīliñ erzān Tārumār olurduḳ biz dahi çün ehl-i ḳarīm

29. Yeñiden virdi bize feyż-i hayāāt-ı iḥsānı̃ Nefh̆ -i Rūḥu'l-ḳuds-āsā idüp iḥyā-yı remīm

30. İtse bir kerre iṣābet naẓar-ı yümn-i esereriñ İder iksīr gibi ferş-i ruhāmı zer ü sīm

31. Hูāzin-i cennet olur keyf ile sermest-i șafā Būy-ı ḩulḳuñla șabā eylese ger neşr-i şemīm 
32. Sāde bir biz mi bütün ‘āleme hụukmüñ cārī

Behre-dār-ı kerem ü ‘āṭfetiñ her iḳlīm

33. Hind ü Sind ü Yemen Belh ü Buhārā Afḡān

İtmededir geh geh 'arż-ı 'ināyet terḳīm

34. Hüüsn-i îfā-yı teşekkür içün itdik biz de

Der-i dergāh-ı felek-cāhıña maẓhar-ı tanẓīm

35. Oldugumdan kerem ü luțuñ ile perverde

Eyledim başḳaca bir țarafa ḳaṣīde taḳdīm

36. İdelim şām u seḥer ḩayr du'ā ey Tevfị̣

Böyledir 'ādet-i derīne-i her 'abd-i ḳadīm

37. Ḥıf̣̣ ide zāāını evlādını Mevlā dā’im

Tā ki ma'mūr ola küngüre-i ‘arş-ı 'aẓīm

\section{Kaynakça}

Altındaş, Eylem Tekemen. (2018). 19. Yüzyılda Osmanlı Devleti’nde Yaşanan Kuraklığın Ankara’ya Yansıması, Çanakkale Araştırmaları Türk Yıllı̆̆ı, C. 16, S. 24, 1-13, Çanakkale.

Azamat, Nihat. (1993). Çerkeşî Mustafa Efendi, DİA, C.8, Türkiye Diyanet Vakfı Yayınları, İstanbul.

Çerkeşîzâde Mehmet Tevfîk. (1304). Kasâid-i Tevfìk, İstanbul.

Eliaçı, Muhittin. (2011). Çerkeşîzâde Mehmet Tevfîk Efendi”nin Vatan Kasîdesi, Çankurı Karatekin Üniversitesi Sosyal Bilimler Enstitüsü Dergisi, 2 (1), 51-73, Çankırı.

Erler, Mehmet Yavuz. (2012) Osmanlı Devleti’nde Kuraklık ve Kıtlık Olayları (1800-1880), İstanbul: Libra Yayınları.

Karaboğa, Durmuş Volkan. (2012). Klasik Dönemde Osmanlı Devleti’nde Tarıma Etki Eden Faktörler Ve Bu Faktörlerin Ortaya Çıkardığı Sonuçlar, International Journal of Social Science, Volume 5, Issue 6, December 2012, ss. 313-327.

Tümertekin, Erol. (1955). Türkiye Kurak Bölgelerinde Buğday Yetiştirme Devresi ile Kurak Devre Arasındaki Zaman Münasebeti, Türkiye Coğrafya Dergisi, C. 3, 13, ss. 107-127.

Yeşil, Şeyma. (2013). Çerkeşîzâde Mehmet Tevfîk Efendi ve Kasâid-i Tevfîk’i, Yüksek Lisans Tezi, Ankara Üniversitesi Sosyal Bilimler Enstitüsü İslam Tarihi ve Sanatları Anabilim Dalı, Ankara. 